\title{
The oblique effect: Interactions with visual persistence and spatial configuration
}

\author{
GEORGIA L'HOMMEDIEU \\ State University of New York, Buffalo, New York 14222 \\ and \\ GLENN E. MEYER \\ Lewis and Clark College, Portland, Oregon 97219
}

\begin{abstract}
Experiment 1 measured the perceived duration of 50-msec exposures of vertical, horizontal, 135-deg, and 45-deg line segments and diamonds and squares formed from these lines. The oblique lines generated longer estimates of visual persistence than the other stimuli did. Experiment 2 replicated these results for stimulus durations of 50-500 msec. Also, parallel persistence by stimulus duration functions were found, indicating a cortical locus for these effects. The results are discussed in light of current theories of visual persistence and the oblique effect.
\end{abstract}

It is well known that obliquely oriented visual stimuli are not as well perceived as vertical or horizontal targets (Appelle, 1972) due to central processes (Maffei \& Campbell, 1970).

This study investigates the influence of the "oblique" effect and the spatial configuration of obliques on persistence. Previous data suggest that visual persistence can be critically dependent on the spatial characteristics of the target, with persistence increasing with spatial frequency (Bowling \& Lovegrove, 1981; Lovegrove, Bowling, \& Gannon, 1981; Meyer, Lawson, \& Cohen, 1975; Meyer \& Maguire, 1977).

These last data have an interesting correlate. Breitmeyer (1975) reports that reaction time to gratings increases with spatial frequency similarly to persistence (Meyer \& Maguire, 1977). All these findings have been related to sustained and transient visual systems. Similarly, oblique reaction times are longer than vertical and horizontal reaction times (L'Hommedieu-Vitale \& Meyer, Note 1). Persistence estimates for oblique targets are longer than are those for vertical and horizontal targets (Bowling \& Lovegrove, 1981; Lovegrove et al., 1981; Meyer, Note 2).

Recently, it also has been reported that a more "cognitive" spatial configuration can influence processing time. Detection of a line target is faster in an object-like configuration (Pomerantz, Sager, \& Stoever, 1977).

Parts of these data were presented at the meeting of the Association for Research in Vision and Opthalmology, Sarasota, Florida, April 1977. Experiment 2 was conducted while Glenn E. Meyer was at the Division of Neurobiology, School of Medicine, State University of New York at Buffalo, Amherst, New York 14226, and supported by National Eye Institute Grant 5T32 EY07019-01. Requests for reprints should be sent to Glenn E. Meyer, Department of Psychology, Lewis and Clark College, Portland, Oregon 97219.
A. Williams and Weisstein (Note 3) and M. C. Williams and Weisstein (1981) used object and nonobject masks in metacontrast; U-shaped functions were obtained, but the ISI for maximal masking was longer for the object masks, indicating faster processing. U-shaped metacontrast masking functions have been tied also to the sustained and transient distinction (Breitmeyer \& Ganz, 1976; Weisstein, Ozog, \& Szoc, 1975), with the mask being processed through faster transient channels. This leads to the question, "Are objects better stimuli for transient systems, and why should this be so?" Whatever the case, would the decrease in response time for objects be reflected in a visual persistence task with more objectlike target configurations? At least one model of visual persistence (DiLollo, 1980) suggests that faster processing leads to shortened persistence. To test these possibilities, vertical, horizontal, and oblique line targets, as well as these same lines combined to produce vertical/horizontal squares and oblique diamonds, were used in a task designed to measure visual persistence.

\section{EXPERIMENT 1}

\section{Method}

Subjects. Seventeen undergraduate students, naive to the purpose of the experiment and with normal or corrected acuity, were tested.

Stimuli and Procedure. The stimuli were presented in a Scientific Prototype three-channel tachistoscope. Six targets were used. Four consisted of $2.2 \times .2 \mathrm{deg}$ black lines of .9 contrast, centered in the field and oriented horizontally, vertically, or at $45 \mathrm{deg}$ or $135 \mathrm{deg}$. The remaining two were a $2.2 \times 2.2 \mathrm{deg}$ square and diamond composed of the verticals/horizontals and obliques. The diamond and square were identical except for rotation. A small fixation point was always visible in the center of these last two objects. Mean luminance was $2.5 \mathrm{fL}$.

The technique used to measure visual persistence has been previously described by Meyer et al. (1975). A target was presented for $50 \mathrm{msec}$ and alternated with a variable-duration blank 


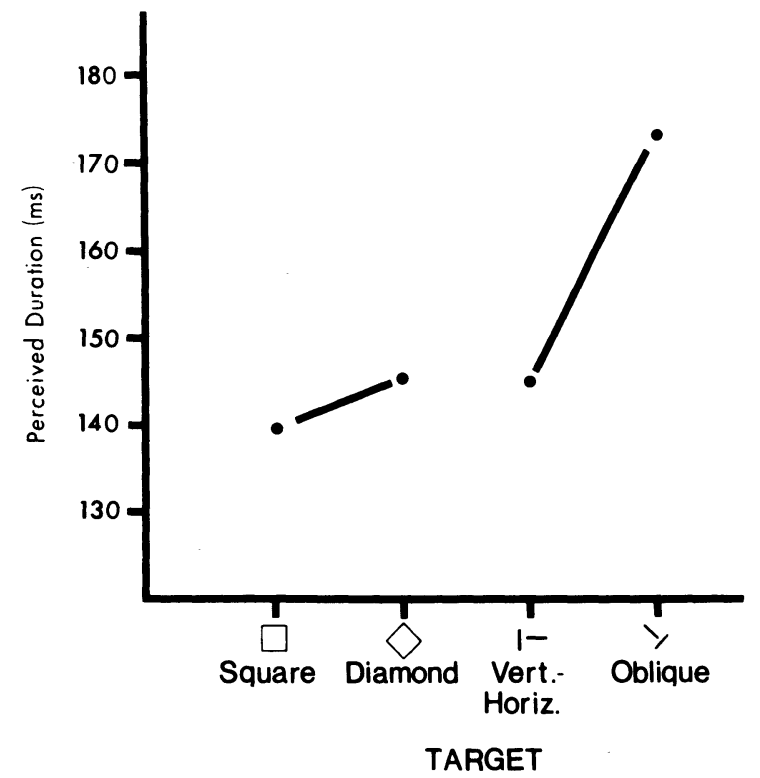

Figure 1. Mean visual persistence or STVS duration estimates $(N=17)$ in response to square, diamond or vertical, horizontal, and oblique line segments presented for $50 \mathrm{msec}$. Verticalhorizontal and 45-deg/135-deg oblique conditions were combined (see text).

field of the same mean luminance. The duration of the blank interval at which the target's appearance changed from continu ously present to discontinuity was our measure of persistence.

Each of the six targets was presented 16 times to a subject. In half the trials, the blank interval was initially short and the target appeared continuous. The experimenter increased the blank duration until the stimulus appeared discontinuous. For the other trials, the target was changed from discontinuity to continuity. Presentation order was appropriately counterbalanced.

\section{Results}

There were no significant differences between the vertical and horizontal targets or between the 45-deg and 135-deg lines, so these pairs were combined for analysis. The data are presented in Figure 1. A within-subjects ANOVA computed on the means of each subject over the four targets was significant $[\mathrm{F}(3,48)=3.24, \mathrm{p}<.05]$. Oblique lines in isolation generated the longest icons. When obliques were combined to form a diamond, the perceived duration dramatically decreased.

\section{Discussion}

The oblique lines produced longest persistence. The cognitive aspects of spatial configuration also had some influence in the case of the diamond. This target contained the same orientations as the single obliques, but its persistence was lowered to the level of the vertical/horizontal lines and the square. This might reflect faster processing, yielding shorter visual persistence.

\section{EXPERIMENT 2: STIMULUS DURATION EFFECTS}

Visual persistence produced by a target usually decreases as the target's duration increases (Bowen, Pola, \& Matin, 1974; DiLollo, 1980; Efron, 1970). Meyer and Maguire (1981) found this was most marked with high spatial frequencies. Bowling and Lovegrove (1981) found this function was parallel for obliques vs. verticals and horizontals.

Bowling and Lovegrove (1981) suggested that their parallel persistence by duration functions indicated that the oblique effect influenced a later cortical component of persistence. At this level, spatial frequency, contrast, and orientation affect persistence. It would seem a change in spatial configuration to produce squares and diamonds would have a "cortical impact." We examined these phenomena with our line and object targets. If our results are similar to Bowling and Lovegrove's (1981), we might expect parallel persistence vs. duration functions.

\section{Method}

Subjects. The two authors, G.L. and G.E.M., served as subjects. G.L. has normal vision, and G.E.M. has a corrected myopic astigmatism.

Stimuli and Procedure. The same stimuli used in Experiment 1 were again presented. Mean luminance was $14.1 \mathrm{fL}$. The same method was used to obtain visual persistence judgments. However, target durations were 50,250 , or $500 \mathrm{msec}$ on different trials. On 1 day, the subjects estimated the visual persistence for the vertical, horizontal, 135-deg, and 45-deg lines. On a different day, they viewed the diamond and square. Six estimates were made for each target and duration combination. Relevant presentation order conditions were randomized and counterbalanced.

\section{Results}

The data for the vertical/horizontal and for the 135-deg/45-deg lines were again combined. The visual persistence judgments for the three target durations are presented in Figure 2. For G.E.M., the main effect of orientation (vertical/horizontal vs. oblique) was significant $[F(1,70)=25.32, p<.01]$, as was the effect of target duration $[\mathrm{F}(2,70)=20.54, \mathrm{p}<.01]$. The interaction of Target Duration by Orientation was not significant $[F(2,70)=1.68, p>.05]$. Similarly for G.L., orientation $[\mathrm{F}(1,70)=76.10, \mathrm{p}<.01]$ and target duration $[F(2,70)=4.48, \mathrm{p}<.05]$ were significant, but the Orientation by Target Duration interaction was not $[F(2,70)=2.56, p>.05]$. Thus, for both subjects, oblique lines produced longer estimates of visual persistence and increasing target duration decreased persistence of targets in a similar manner.

For G.L., neither the effect of orientation (diamond vs. square) $[\mathrm{F} 1 ; 34)=.25, \mathrm{p}<.05]$ nor the Orientation by Target Duration interactions $[\mathrm{F}(2,34)=.08$, $\mathrm{p}>.05]$ was significant. Only the target duration main effect manifested significance $[F(2,34)=10.62$, $\mathrm{p}<.01]$. G.E.M. showed a similar pattern, as the target duration effect was significant $[F(2,34)=4.88, p<.05]$ but the orientation main effect $[F(1,34)=.10, p>.05]$ and the Target Duration by Orientation (square/ diamond) interaction $[F(2,34)=.05, p>.05]$ were not.

\section{Discussion}

We replicated the findings of Experiment 1. Also, persistence for all targets decreased as target duration increased with similar rates of decline. These parallel functions agree with Bowling and Lovegrove's (1981) analyses. The cortical component of persistence seems to be influenced. 

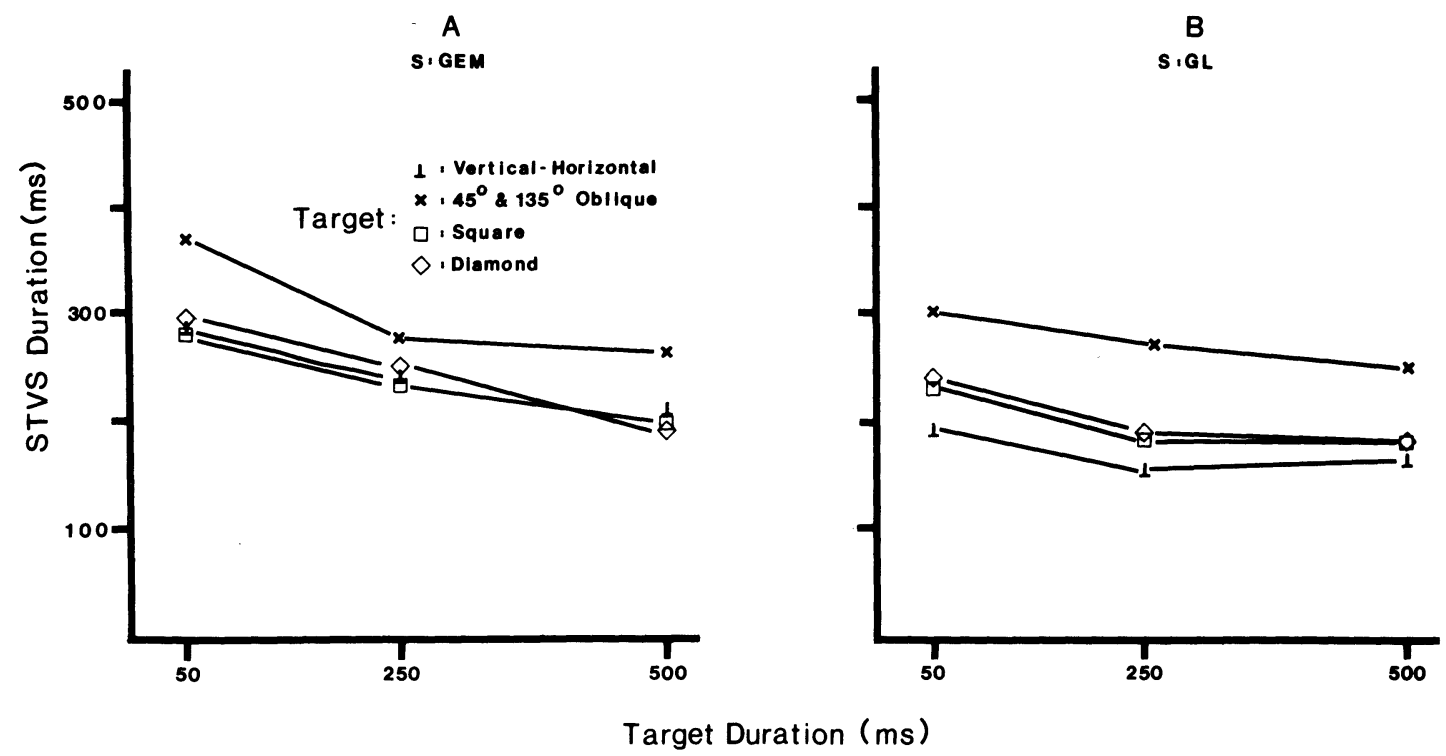

Figure 2. Mean visual persistence or STVS duration estimates for G.E.M. and G.L. in response to square, diamond, or vertical, horizontal, and oblique line segments presented for 50, 250, and $500 \mathrm{msec}$. Vertical-horizontal and 45-deg/ 135-deg oblique conditions were combined (see text).

Our previous research suggested that longer persistence is linked to sustained systems. However, tying this experiment directly into the sustained/transient system distinction is difficult. It is not obvious why an object-like configuration would be better stimulu s for transient systems (if you tie decreased persistence to a transient response). The " $\mathrm{X}$ " vs. " $Y$ " dichotomy begins in the retina, and it does not seem likely that ganglion cells start differentiating between objects and nonobjects. It would seem such "object-superiority" effects must reflect higher level processing. This is especially true of metacontrast results (A. Williams \& Weisstein, Note 3). Since metacontrast can be obtained dichoptically, the actual inhibitory interaction would seem to be cortical, but the fast transmission necessitated by U-shaped functions is postulated to be in "Y" systems. Thus, if objects are handled differently from nonobjects in the retinogenticulate-striate pathway, it is not clear that this can be explicitly linked to transient vs. sustained systems at this time and how "objectness" fits into these metacontrast models. M. C. Williams and Weisstein (1981) report that apparent depth can decrease the locus of the " $U$ " minimum of metacontrast even for low-frequency masks. This suggests a high-level effect of organization that is not easily tied to a simple sustainedtransient dichotomy.

We are left with interesting correlations, such as that between reaction time and persistence. We know that luminance increases shorten reaction time (Kohfeld, 1971) and visual persistence (Bowen et al., 1974), increasing spatial frequency increases reaction time (Breitmeyer, 1975) and visual persistence (Meyer \& Maguire, 1977), oblique orientations increase reaction time (L'Hommedieu-Vitale \& Meyer, Note 1) and persistence (this study; Bowling \& Lovegrove, 1981), and "objectness" (an admittedly ill-defined term) decreases reaction time (Pomerantz et al., 1977) and persistence (at least for diamonds vs. obliques in the present Experiments 1 and 2). These are suggestive, and at least one model of visual persistence (DiLollo, 1980) predicts, that faster perceptual processing decreases persistence. Bowling and Lovegrove (1981) suggest that the oblique effect in persistence represents, therefore, weaker oblique processing. It is well known that "weaker" stimuli have longer persistences. However, this relationship is not causal but correlative and certainly not ironclad. For instance, we know that orien tation-specific adaptation with grating stimuli increases reaction time (Furchner \&
Young, 1975) but similar adaptation decreases iconic duration (Meyer et al., 1975). As Coltheart (1980) cogently pointed out, the simple box of sensory storage in our earlier flowcharts has fragmented explosively.

\section{REFERENCE NOTES}

1. L'Hommedieu-Vitale, G., \& Meyer, G. E. Obliques and object superiority: Interaction of effects on the perceived duration of lines. Paper presented at the meeting of the Association for Research in Vision and Ophthalmology, Sarasota, Florida, 1977.

2. Meyer, G. E. Spatial configuration and visual persistence. Paper presented at the meeting of the Western Psychological Association, San Francisco, California, 1978.

3. Williams, A., \& Weisstein, N. Effects of overall structure on the temporal course of masking a simple detection task. Paper presented at the meeting of the Association for Research in Vision and Ophthalmology, Sarasota, Florida, 1977.

\section{REFERENCES}

Appelle, S. Perception and discrimination as a function of stimulus orientation: The "oblique effect" in man and animals. Psychological Bulletin, 1972, 78, 266-278.

Bowen, R. W., Pola, J., \& Matin, L. Visual persistence: Effects of flash luminance, duration and energy. Vision Research, 1974, 14, 195-303.

Bowling, A., \& Lovegrove, W. Two components to visible persistence: Effects of orientation and contrast. Vision Research, 1981, 21, 1241-1251.

Breitmeyer, B. G. Simple reaction time as a measure of the temporal response properties of transient and sustained channels. Vision Research, 1975, 15, 1411-1412.

BRE ITMEYER, B. G., \& GANZ, L. Implications of sustained and transient channels for theories of visual pattern masking, saccadic suppression and information processing. Psychological Review, 1976, 83, 1-36.

Colthe art, M. Iconic memory and visual persistence. Perception \& Psychophysics, 1980, 27, 183-228.

DiLollo, V. Temporal integration in visual memory. Journal of Experimental Psychology: General, 1980, 109, $75-97$. 
Erron, R. The relationship between the duration of a stimulus and the duration of a perception. Neuropsychologia, 1970, 8, 37-55.

Furchner, C. S., \& Young, S. J. Recovery from adaptation as a function of stimulus orientation. Perception \& Psychophysics, 1975, 17, 117-124.

KoHFELD, D. L. Simple reaction time as a function of stimulus intensity in decibels of light and sound. Journal of Experimental Psychology, 1971, 88, 251-257.

Lovegrove, W., Bowling, A., \& Gannon, S. Orientation specificity in the visible persistence for checkerboards. Vision Research, 1981, 21, 1239-1240.

MAfFe I, L., \& CAmpBeld, F. W. Neurophysiological localization of the vertical and horizontal visual coordinates in man. Science, 1970, 167, 386-387.

Meyer, G. E., Lawson, R., \& Cohen, W. The effects of orientation specific adaptation on the duration of short term visual storage. Vision Research, 1975, 15, 569-572.

Meyer, G. E., \& Maguire, W. M. Spatial frequency and the mediation of short term visual storage. Science, 1977, 198, 524-525.

Meyer, G. E., \& Maguire, W. M. Visual persistence: Effects of spatial frequency, target duration and adaptation. Journal of Experimental Psychology: Human Perception and Performance, 1981, 7, 151-156.

Pomerantz, J. R., Sager, L. C., \& Stoever, R. G. Perception of wholes and their component parts: Some configural superiority. Journal of Experimental Psychology: Human Perception and Performance, 1977, 3, 422-435.

Williams, M. C., \& Weisstein, N. Spatial frequency response and perceived depth in the time course of object superiority. Vision Research, 1981, 21, 631-646.

Weisstein, N., Ozog, G., \& Szoc, R. A comparison and elaboration of two models of metacontrast. Psychological Review, $1975,82,325-442$.

(Received for publication April 29, 1982.) 